\title{
Correction to: Effective Tools for Pedagogical Change in Religious Education: Experience of Teachers in Hong Kong Catholic Kindergartens and Primary Schools
}

\author{
Wing Kay Vion Ng and Shuet Yan Fion Luk
}

\section{Correction to:}

Chapter 24 in: M. T. Buchanan and A.-M. Gellel (eds.), Global Perspectives on Catholic Religious Education in Schools, https://doi.org/10.1007/978-981-13-6127-2_24

In the original version of the book, the chapter authors' given and family names were corrected from N. G. Vion Wing Kay and L. U. K. Fion Shuet Yan to Wing Kay Vion Ng and Shuet Yan Fion Luk, respectively. Also, the organization name of the second author, Shuet Yan Fion Luk, was corrected from Caritas Religious and Spiritual Life Education Unit to Caritas Institute of Higher Education. The book has been updated with the changes. 